\title{
FREQUENCY OF BLOOD GROUP SUB-TYPE IN PATIENTS WITH ISCHEMIC STROKE AT NISHTAR HOSPITAL MULTAN.
}

\footnotetext{
1. MBBS, MCPS, FCPS Assistant Professor Med Unit 2, Nishtar Hospital Multan 2. MBBS, FCPS (Med) Senior Registrar Department of Medicine Nishtar Hospital Multan 3. MBBS

Medical Officer

Department of Med Unit 2, Nishtar Hospital Multan.
}

Correspondence Address: Dr. Muhammad Tahir

Al Quresh Phase-1 Sher Shah Road Street No.8 House No. 231 Multan tahirch77@gmail.com

Article received on: 12/09/2018 Accepted for publication: 15/02/2019 Received after proof reading: $31 / 07 / 2019$

\begin{abstract}
Muhammad Tahir $^{1}$, Gohar Ali $^{2}$, Ali Ismail ${ }^{3}$
ABSTRACT... The objective of this study was to determine the blood groups among the patients presenting with ischemic stroke either $A B$ blood group or $O$ blood group is more common (frequent) among these patients irrespective of other known factors responsible for stroke. Study Design: Descriptive, Cross-sectional study. Setting: Department of Medicine, Nishtar Hospital Multan. Period: January 2015 to August 2015. Materials \& Methods: We included total 292 patients (40-70 years of age), with ischemic stroke documented on CT scan brain of both gender (male and female). Blood sample of these patients were sent to the central laboratory of Nishtar hospital for blood group determination using standard techniques. Results: Mean age was $56.26 \pm 8.28$ years. Out of the 292 patients, $163(55.82 \%)$ were male and 129 (44.18\%). Frequency of blood group A, B, AB and O in patients with ischemic stroke was found to be 114 patients having blood group $A(39.04 \%), 53$ patients having blood group B (18.15\%), 26 patients having blood group $A B(8.90 \%)$ and 99 patients having blood group $\mathrm{O}(33.90 \%)$ respectively. Conclusion: Our study results concluded that there is an association between $A B O$ blood groups and ischemic stroke, irrespective of other risk factors. Our study results have observed that individuals belonging to non-O blood groups $(A, B$, or $A B)$ are at an increased risk of ischemic stroke as compared to $O$ blood group carriers however we did not control possible impact of confounders such as diabetes, hypertension and dyslipidemia etc. Many studies proved that persons with $\mathrm{AB}$ blood groups are at increased of atherosclerosis but no study showed that these persons have increased risk of ischemic stroke or not.
\end{abstract}

Key words: $\quad$ Atherosclerosis, ABO Blood Groups, Pakistan, Ischemic Stroke.

Article Citation: Tahir M, Ali G, Ismail A. Frequency of blood group sub-type in patients with ischemic stroke at Nishtar Hospital Multan. Professional Med J 2019; 26(8):1333-1338. DOI: 10.29309/TPMJ/2019.26.08.3879

\section{INTRODUCTION}

Stroke is defined as any rapidly developing deficit of a part or whole side of body that persists more than 24 hours. ${ }^{1}$ It is either Hemorrhagic or Ischemic that leads to decreased supply of blood and nutrients to that part of brain. ${ }^{2}$ Approximately more than 15 million people suffer from stroke all across the world, of which one third of them dies and one third suffers from disability. In developing countries, stroke is the third most common cause of mortality, only coronary heart disease and cancers causes more death than stroke. ${ }^{3} 85 \%$ of all cases of stroke are disagnosed as ischemic sub-type. ${ }^{4}$ Study in United States showed that 0.8 million people have stroke each year in United States and as high $82-92 \%$ among them were have ischemic stroke. ${ }^{5}$ The two major causes of Ischemic Stroke are Atherosclerosis and embolism followed by vasculitis, endocarditis and venous infarcts are the other causes of ischemic stroke..$^{6,7,8}$ It is very important to know underlying cause as the subsequent management of each patient depends on the sub type of stroke. The most important diagnostic test is Neuroimaging (CT-Scan brain) in not only in the early diagnosis of stroke type but also further management and treatment of the patient depends on it. ${ }^{9}$ If the patient have ischemic stroke tissue plasminogen activator is the treatment of choice provided the patient arrives with 3 hour of symptoms. ${ }^{10}$

ABO Blood group was discovered in $19^{\text {th }}$ century by Landsteiner that is based on presence or absence of the two genes, A \& B which produces antigens $A$ \& $B$ respectively while absence of such antigen where classified as having blood group $\mathrm{O}$. 
This system produced four types of blood groups with $\mathrm{O}$ group the most common with $44 \%$, closely followed by $A$ group at $43 \%$, $B$ group is $4 \%$ and AB group is $19 \% .{ }^{11}$ Initially $A B O$ blood group knowledge was only use to avoid reactions during blood transfusion however recent development have studied the role of blood group subtypes in different diseases like atherosclerosis, MI, stroke, diabetes, peptic ulcer and even cancers. Gong $P$ along with other authors in his study noted that there was increase risk of atherosclerosis with non o blood group. ${ }^{12,13}$ Sabino AP et al showed that different blood groups behave differently for ischemic stroke and peripheral arterial disease and finding non-O blood group such as $A, B$ or $A B$ were more prevalent in patients with atherosclerosis, MI, Stroke. ${ }^{14}$ Hanson $\mathrm{E}$ et al ${ }^{15}$ in his study also echoed Sabino studied and showed that ischemic stroke is more prevalent in patients with blood group A. While internationally there is ample data but no such study is available in Pakistan.

The rational of this study was to determine which blood groups are more prevalent among patients presenting with ischemic stroke irrespective of other risk factors and further studies can be conducted to figure if specific blood groups can be an associated with ischemic stroke.

\section{MATERIALS \& METHODS}

This was a descriptive, Cross-sectional study, conducted in the department of medicine, Nishtar Hospital Multan from January 2015 to August 2015 with permission from ethical and Research board of hospital with consent of patients having ischemic stroke of both genders and $40-70$ years of age. Those who were having head trauma or hemorrhage on neuro imaging were excluded. Non-probability, Consecutive sampling used by taking following values

$\mathrm{n}=\mathrm{z}^{z} \mathrm{p}(1-\mathrm{p}) / \mathrm{e}^{2} \mathrm{n}=(1.96)^{2} \quad 0.05(1-0.05) /$ $(0.025)^{2}=292$

Where $p=$ Frequency of $A B O$ blood groups among patients with ischemic stroke $=5 \% .{ }^{15}$ $\mathrm{e}=$ margin of error $=2.5 \%$.

Of these 292 patients with ischemic stroke admitted to, Nishtar Hospital Multan, fulfilling the inclusion/exclusion criteria was selected. After taking consent, blood samples taken from peripheral vein for blood grouping were sent to the Central Laboratory Nishtar Hospital Multan. Laboratory technician determined blood group using standard techniques. All this information was collected through a self structured Performa.

All data were processed and analyzed using computer based software program SPSS version 22.0 for windows. Numerical variables like age have been presented by calculating as mean and standard deviation. Qualitative data like gender, ABO blood group have been presented by calculating frequency and percentage. Effect modifiers like age, gender and family history of ischemic stroke (yes/no) have been controlled after making stratification tables and poststratification chi square was applied to see their effect on outcome and P-value $\leq 0.05$ has been taken as significant.

\section{RESULTS}

Participants in our study were from age range 40 to 70 years with mean age of $56.26 \pm 8.28$ years. Majority of the patients 123 (42.12\%) were between 51 to 60 years of age as shown in Table-l. Out of the 292 patients, 163 (55.82\%) were male and 129 (44.18\%) were females with male to female ratio of 1.3:1 (Figure-1).

The prevalence of blood group $A, B, A B$ and $O$ in patients with ischemic stroke was found to be as of following; 114 patients having blood group A (39.04\%), 53 patients having blood group B (18.15\%), 26 patients having blood group $A B(8.90 \%)$ and 99 patients having blood group $O(33.90 \%)$ respectively (Figure-2). When Stratification of blood groups was done on age groups, significant difference was found between different age groups as shown in Table-II while the stratification of blood groups with respect to gender has shown in Table-III which showed no significant difference between male and female. Table IV has shown the stratification of blood groups with respect to family history of ischemic stroke. 


\begin{tabular}{|c|c|c|}
\hline Age (in Years) & No. of Patients & \%age \\
\hline $40-50$ & 74 & 25.34 \\
\hline $51-60$ & 123 & 42.12 \\
\hline $61-70$ & 95 & 32.53 \\
\hline
\end{tabular}

Table-I: Age distribution of patients $(n=292)$.
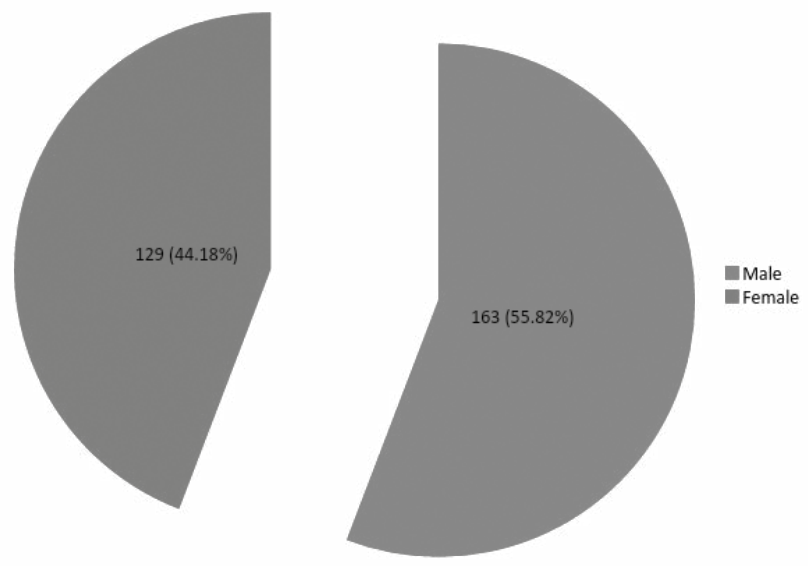

Figure-1. \%age of patients according to gender $(n=292)$.

\section{DISCUSSION}

Numerous studies have proven that thrombosis is not just a regular process for blood coagulation but it is controlled by genetics and various genetic variants play their role in process of blood coagulation. ${ }^{16,17}$

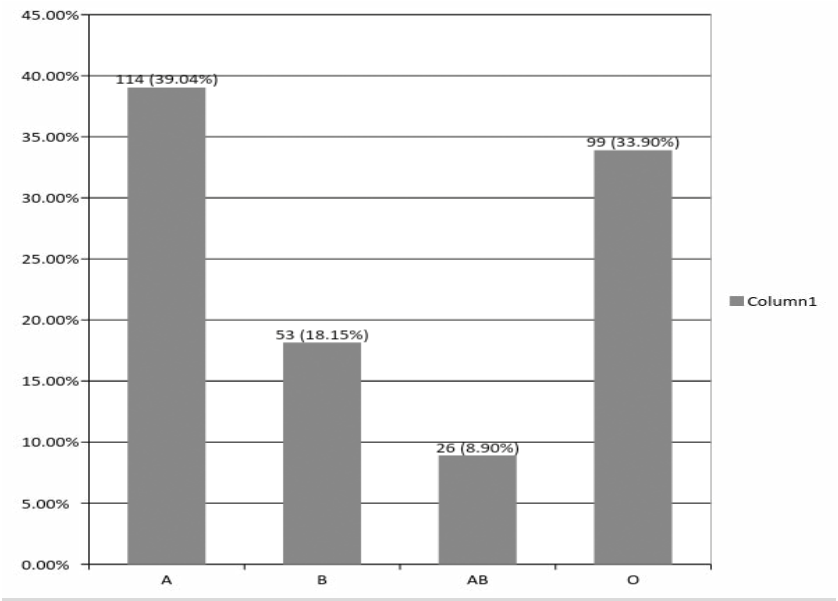

Figure-2. \%age of patients according to $A B O$ blood group $(n=292)$

This genetic variation and influence is not only limited to structure but function of thrombosis, such as fibrin and other factors for formation and lysis of thrombosis, is also based on it. ${ }^{18,19}$ Thrombosis in brain is the leading cause of death and morbidities in developed nations. ${ }^{16}$ ABO blood group systems comprises of different antigens which are present on RBS and vascular endothelium, and these blood groups have proven links with procoagulant proteins like factor IV and won villibrand factors and many more, hence playing an important role in thrombus formation. ${ }^{20-22}$

\begin{tabular}{|c|c|c|c|c|c|}
\hline \multirow{2}{*}{ Age (Years) } & \multicolumn{4}{|c|}{ Blood Group } & \multirow{2}{*}{ P-Value } \\
\hline & A & B & $A B$ & 0 & \\
\hline $40-50$ & 27 (36.49\%) & $18(24.32 \%)$ & $10(13.51 \%)$ & 19 (25.68\%) & \multirow{3}{*}{0.000} \\
\hline $51-60$ & 50 (40.65\%) & 43 (34.96\%) & 06 (4.88\%) & $24(19.51 \%)$ & \\
\hline $61-70$ & 37 (38.95\%) & 10 (10.53\%) & $10(10.53 \%)$ & 38 (40.0\%) & \\
\hline
\end{tabular}

Table-II. Stratification of Blood groups with respect to age groups.

\begin{tabular}{|c|c|c|c|c|c|}
\hline \multirow{2}{*}{ Gender } & \multicolumn{4}{|c|}{ Blood Group } & \multirow{2}{*}{ P-Value } \\
\hline & A & B & AB & 0 & \\
\hline Male & $54(33.13 \%)$ & $59(36.20 \%)$ & $18(11.04 \%)$ & $32(19.63 \%)$ & \multirow{2}{*}{0.102} \\
\hline Female & $60(46.51 \%)$ & $40(31.01 \%)$ & $08(6.20 \%)$ & $21(16.28 \%)$ & \\
\hline \multicolumn{6}{|c|}{ Table-III. Stratification of blood groups with respect to age gender. } \\
\hline \multirow{2}{*}{ Family History } & \multicolumn{4}{|c|}{ Blood Group } & \multirow{2}{*}{ P-Value } \\
\hline & A & B & AB & 0 & \\
\hline Yes & $64(45.3 \%)$ & $20(14.18 \%)$ & $19(13.4 \%)$ & $38(26.9 \%)$ & \multirow{2}{*}{0.623} \\
\hline No & 50 (33.11\%) & $33(21.8 \%)$ & 07 (4.63\%) & 61 (40.39\%) & \\
\hline
\end{tabular}


Recent developments have shown blood group system that certain blood groups have increase risk of cerebrovascular events like MI and ischemic stroke and their importance goes beyond just blood transfusion and reaction. ${ }^{20}$

Out of the 292 patients, 163 (55.82\%) were male and 129 (44.18\%) were females. In literature, various studies have proven that ischemic stroke is more common in male including a study conducted by Luo et $\mathrm{al}^{23}$ from China which also reports that ischemic stroke is more prevalent in male than in female. Local data also proves the same with a study from Karachi by Sheikh et al24 stated that $61 \%$ of patients with ischemic stroke were males.

The limitations of the study were our inability to remove all confounding factors. Although we controlled for many risk factors for ischemic stroke, but factors such as smoking status, use of medication, High LDL-C, hypertension status was not taken which might have affected the power of study. A larger multi centric study is required to further consolidate the result of my findings.

Age range in this study was from 40 to 70 years with mean age of $56.26 \pm 8.28$ years. Majority of the patients 123 (42.12\%) were between 51 to 60 years of age. Other similar studies such as Khan et al ${ }^{25}$ (58.11 \pm 15.29$)$ and Abid et al ${ }^{26}$ (55.96 \pm 13.75) had a demographic profiles that matched our study.

In our study, frequency of blood group $A, B, A B$ and $O$ was found to be 114 (39.04\%), 53 (18.15\%), 26 (8.90\%) and 99 (33.90\%) respectively. Hanson $\mathrm{E}$ et $\mathrm{al}^{15}$ in his study has shown the frequency of blood group $\mathrm{A}, \mathrm{B}, \mathrm{AB}$ and $\mathrm{O}$ as $47 \%, 14 \%, 5 \%$ and $34 \%$ respectively in patients of ischemic stroke, results are closer to our study results. He $\mathrm{M}$ et al showed that $\mathrm{ABO}$ blood type is strongly associated with venous thromboembolism (VTE) and weakly association with myocardial infarction. ${ }^{27}$ In a genetic study Wiggins $\mathrm{KL}$ proved that hypertensive or post-menopausal woman with the alleles for $A$ and $B$ Blood groups have greater incidence of myocardial infarction, stroke, and VTE risk. ${ }^{28}$ Sabino AP et al ${ }^{14}$ observed that non-O blood group have greater and more significant association with Ischemic stroke.. Zakai NAet al ${ }^{13}$ again showed that $A B$ blood group is associated with increased risk of ischemic stroke. In his study the most prevalent blood group in patients with ischemic stroke was A blood group with $43 \%$ followed by Blood Group O (39.6\%). Wiggins KL tried to find association between blood group sub type and diseases such as venous thrombosis and ischemic stroke. His result stated that blood group $A$ and $B$ had an increased risk of venous thrombosis and Ischemic stroke in comparison to blood group $\mathrm{O}^{28}$ Williams $\mathrm{FM}$ along with his colleagues showed that $\mathrm{ABO}$ gene variants plays a role in large vessel and cardio embolic stroke but not the small vessel diseas. ${ }^{29}$ A metaanalysis comprising of seven studies consisting of patients who had different type of strokes before age 70 stated that there was significantly enhanced of stroke for the patients having non-O blood group as compared with those of having $\mathrm{O}$ blood group. ${ }^{30}$

Zhou $S$ et $\mathrm{al}^{31}$ in his study quality of VWF and FVIII is determined by Locus $A B O$, hence which in turn determines the risk of VTE in patient. People with blood group $\mathrm{O}$ have the lowest risk of VTE. ${ }^{31}$ To summarize it can be said that there is an association between ABO blood groups and ischemic stroke, with people with blood group $A, B$ or $A B$ are at greater risk of ischemic stroke compared to those with blood group $\mathrm{O}$.

\section{CONCLUSION}

Our study results concluded that there is an association between ABO blood groups and ischemic stroke. Our study results have observed that individuals belonging to non-O blood groups $(A, B$, or $A B)$ are at an increased risk of ischemic stroke as compared to $O$ blood group carriers however we did not control possible impact of confounders such as diabetes, hypertension and dyslipidemia. Further studies are required to see this observation and to prove this as independent risk factor for ischemic stroke.

Copyright $@ 15$ Feb, 2019. 


\section{REFERENCES}

1. Fonarow GC, Saver JL, Smith EE, Broderick JP, Kleindorfer DO, Sacco RL, et al. Relationship of national institutes of health stroke scale to 30 day mortality in medicare beneficiaries with acute ischemic stroke. J Am Heart Assoc. 2012; 1(1):42-50.

2. Arshi S, Naheed F, Badshah M, Naz F, Nisa F. Hemorrhagic and ischemic stroke; Frequency in hypertensive patients presenting with stroke at Pakistan Institute of Medical Sciences, Islamabad. Professional Med J. 2012; 19(3):1-5.

3. Go AS, Mozaffarian D, Roger VL, Benjamin EJ, Berry JD, Borden WB. Heart disease and stroke statistics-2013 update: A report from the American Heart Association. Circulation. 2012:e2-241.

4. Bushnell C, McCullough LD, Awad IA, Chireau MV, Fedder WN, Furie $\mathrm{KL}$, et al. Guidelines for the prevention of stroke in women: A statement for healthcare professionals from the American Heart Association/American Stroke Association. Stroke. 2014; 45(5):1545-88.

5. Roger VL, Go AS, Lloyd-Jones DM, Benjamin EJ, Berry JD, Borden WB, et al. Heart disease and stroke statistics--2012 update: A report from the American Heart Association. Circulation. 2012; 125(1):e2-e220.

6. Bilal MH, Tahir M, Khan NA. ACUTE STROKE. The Professional Medical Journal. 2016 Jul 10;23(07):78994.

7. Mullins ME, Lev MH, Schellingerhout D, Gonzalez RG, Schaefer PW. Intracranial hemorrhage complicating acute stroke: How common is hemorrhagic stroke on initial head CT scan and how often is initial clinical diagnosis of acute stroke eventually confirmed? AJNR Am J Neuroradiol. Oct 2005; 26(9):2207-12.

8. Nighoghossian $\mathrm{N}$, Hermier $\mathrm{M}$, Adeleine $\mathrm{P}$, BlancLasserre K, Derex L, Honnorat J. Old microbleeds are a potential risk factor for cerebral bleeding after ischemic stroke: A gradient-echo T2-weighted brain MRI study. Stroke. Mar 2002; 33(3):735-42.

9. Dirnagl U, ladecola C, Moskowitz MA. Pathobiology of ischaemic stroke: An integrated view. Trends Neurosci. Sep 1999; 22(9):391-7.

10. Tissue plasminogen activator for acute ischemic stroke. The national institute of neurological disorders and stroke rt-PA stroke study group. $\mathrm{N}$ Engl J Med. Dec 14 1995; 333(24):1581-7.
11. Liumbruno GM, Franchini M. Hemostasis, cancer, and $A B O$ blood group: The most recent evidence of association. J Thromb Haemost. 2013; 38(2):160-66.

12. Yang N, Zhang B, Xie L, Yin J, He Y, Yang X, et al. The association baseline NIH stroke scale score with ABO blood-subtypes in young patients with acute ischemic stroke. Atherosclerosis. 2014; 236(1):144-9.

13. Zakai NA, Judd SE, Alexander K, McClure LA, Kissela $\mathrm{BM}$, Howard $\mathrm{G}$, et al. ABO blood type and stroke risk: The reasons for geographic and racial differences in stroke study. J Thromb Haemost. 2014; 12(4):564-70.

14. Sabino AP, Ribeiro DD, Domingheti CP, Rios DR, Dusse LM, CarvalhoMd, et al. ABO blood group polymorphisms and risk for ischemic stroke and peripheral arterial disease. MolBiol Rep. 2014; 41(3):1771-77.

15. Hanson E, Karlsson S, Jood K, Nilsson S, Blomstrand $C$, Jern $C$. No evidence for an association between ABO blood group and overall ischemic stroke or any of the major etiologic subtypes. Thromb Res. 2012; 130(3):339-42.

16. Lopez $A D$, Mathers $C D$, Ezzati M. Global and regional burden of disease and risk factors, 2001: Systematic analysis of population health data. Lancet 2006; 367:1747-1757.

17. Souto JC, Almasy L, Borrell M, et al. Genetic susceptibility to thrombosis and its relationship to physiological risk factors: The GAIT study. Genetic Analysis of Idiopathic Thrombophilia. Am J Hum Genet 2000; 67:1452-1459.

18. Carter AM, Cymbalista CM, Spector TD, Grant PJ. Heritability of clot formation, morphology, and lysis. The Euro CLOT study. Arterioscler Thromb Vasc Biol 2007; 27:2783-2789.

19. Williams FM, Carter AM, Kato B, et al. Identification of quantitative trait loci for fibrin clot phenotypes: The Euro CLOT study. Arterioscler Thromb Vasc Biol 2009; 29:600-605.

20. Zhang $H$, Mooney $\mathrm{CJ}$, Reilly MP. ABO blood groups and cardiovascular diseases. Int J Vasc Med 2012; 2012: 641917.

21. Ohira T, Cushman M, Tsai MY, Zhang Y, Heckbert SR, Zakai NA, Rosamond WD, Folsom AR. ABO blood group, other risk factors and incidence of venous thromboembolism: The longitudinal investigation of thromboembolism etiology (LITE). J Thromb Haemost 2007; 5: 1455-61. 
22. Barbalic M, Dupuis J, Dehghan A, Bis JC, Hoogeveen $\mathrm{RC}$, Schnabel RB, et al. Large-scale genomic studies reveal central role of $A B O$ in sP-selectin and SICAM-1 levels. Hum Mol Genet 2010; 19:1863-72.

23. "Luo Y, Li J, Zhang $\mathrm{J}^{1}, \mathrm{Xu}$ Y. Low HDL cholesterol is correlated to the acute ischemic stroke with diabetes mellitus. Lipids Health Dis. 2014 Nov 14; 13:171. doi: 10.1186/1476-511X-13-171.

24. Shaikh NA, Bhatty S, Irfan M, Khatri G, Vaswani AS, Jakhrani S. Frequency, characteristics and risk factors of carotid artery stenosis in ischaemic stroke patients. J Pak Med Assoc. 2010; 60(1):8-12".

25. Khan MN, Khan HD, Ahmad M, Umair M. Serum total and HDL-cholesterol in ischemic and hemorrhagic stroke. Ann Pak Inst Med Sci 2014; 10(1)22-26.

26. Abid N, Khan SA, Taseer IH. Frequency of hyperlipidemia in patients presenting with ischemic stroke. Pak J Med Health Sci. 2012; 6(2):423-28."
27. He M, Wolpin B, Rexrode K, Manson JE, Rimm E, Hu $\mathrm{FB}$, Qi L. ABO blood group and risk of coronary heart disease in two prospective cohort studies. Arterioscler Thromb Vasc Biol 2012; 32: 2314-20.

28. Wiggins $\mathrm{KL}$, Smith $\mathrm{NL}$, Glazer NL, Rosendaal FR, Heckbert SR, Psaty BM, Rice KM, Lumley T. ABO genotype and risk of thrombotic events and hemorrhagic stroke. J Thromb Haemost 2009; 7: 2639.

29. Williams FM, Carter AM, Hysi PG, Surdulescu G, Hodgkiss $D$, Soranzo $N$, et al. Ischemic stroke is associated with the ABO locus: The Euro CLOT study. Ann Neurol 2013; 73:16-31.

30. Ionescu DA, Marcu I, Bicescu E. Cerebral thrombosis, cerebral haemorrhage, and $A B O$ blood-groups. Lancet. 1976; 1:278-80.

31. Ling X, Zheng Y, Tao J, Zheng Z, Chen L. Association study of polymorphisms in the $A B O$ gene with ischemic stroke in the Chinese population. BMC Neurol. 2016 Aug 19; 16(1):146.doi: 10.1186/s12883016-0671.

\begin{tabular}{|c|l|l|l|}
\hline \multicolumn{3}{|c|}{ AUTHORSHIP AND CONTRIBUTION DECLARATION } \\
\hline Sr. \# & Author-s Full Name & \multicolumn{1}{|c|}{ Contribution to the paper } & Author=s Signature \\
\hline 1 & Muhammad Tahir & $\begin{array}{l}\text { Planning, Synopsis, Data } \\
\text { collection. } \\
\text { Analysis, Editing, Data collection. }\end{array}$ \\
\hline 2 & Gohar Ali & Writing, Data analysis, Collection. \\
\hline 3 & Ali Ismail & \\
\hline
\end{tabular}

